\title{
A formação do jovem: relação entre os principais estereótipos e a responsabilidade pessoal
}

\author{
Natalia dos Santos Conceição
}

Resumo: O presente trabalho foi elaborado tendo como tema a formação do jovem, demonstrando a relação entre o contexto social em que se encontra e os principais estereótipos. E tem como objetivos evidenciar os comportamentosbase regressivos que consomem a potencialidade do jovem e salientar passagens fundamentais na busca de autoconhecimento e da estrada da própria vida. Para realizar este trabalho, tivemos como metodologia o estudo teórico no viés da Escola Ontopsicológica.

Palavras-chave: Jovem; Estereótipos; Formação; Responsabilidade; Pedagogia Ontopsicológica.

Training of young: relation between the main stereotypes and the personal responsibility

Abstract: The present work was elaborated on the theme of young training, showing the relation between the social context in which the young is and the main stereotypes of the young, aiming to show the regressive base-behaviors que consume the young potentiality and emphasize fundamental passages in the search for self-knowledge and the road of own life. To achieve this, we had as methodology the theorical study in the bias of Ontopsychological School. It is a qualitative research mainly in a theorical study.

Keywords: Young; Stereotypes; Fostering; Responsibility; Ontopsychological Pedagogy.

La formación del jóven: relación entre los principales estereotipos y la responsabilidad personal

Resumen: El presente trabajo fue elaborado con el tema sobre la formación del joven y demostró la relación entre el contexto social en que el joven se encuentra y los principales estereotipos que le rodean. Y tiene como objetivos evidenciar los comportamientos-base regresivos que consumen la potencialidad del joven y relevar pasajes fundamentales en la búsqueda de autoconocimiento y del camino de la propia vida. Para realizar este trabajo, tuvimos como metodología el estudio teórico en el sesgo de la Escuela Ontopsicológica.

Palabras clave: Joven; Formación; Estereotipos; Responsabilidad; Pedagogía Ontopsicológica. 
O presente trabalho tem como temática "A Formação do Jovem: relação entre os principais estereótipos e a responsabilidade pessoal". O mesmo se refere a pontos fundamentais para compreensão da própria identidade, a fim de realizar as passagens adequadas para constituir-se como pessoa íntegra diante de seu próprio projeto de vida e deste na sociedade.

Acreditamos que, uma vez que não somos pessoas totalmente íntegras diante de nosso projeto - por não termos, historicamente, uma consciência reversível ao todo de nosso projeto de vida - muitas vezes não atuamos a potencialidade natural que portamos, não nos tornamos autênticos, realizados, e também não nos tornamos coeficientes de valor da vida. Este é um dos pontos que se refere a nossa motivação em pesquisar o presente assunto, porque a partir do momento em que estivermos disponíveis a nos discutirmos poderemos, por um processo de consultoria de autenticação ${ }^{1}$ individual, realizarmos as diversas metanoias $^{2}$ e revisão crítica de consciência para desenvolvermos um percurso de crescimento em base ao projeto de vida ${ }^{3}$ e inteligência que já somos.

A juventude é o período em que mais possuímos coragem e vontade de viver, mas em contrapartida, encontramo-nos em ambientes/contextos impróprios para cultivarmos a aspiração de viver que sentimos, provinda do seio da vida. A globalização acentua a problemática da deflexão (desvio/distorção da informação) do que realmente somos e a juventude, dessa forma, perde o conceito de o que é o homem.

O bombardeamento de informações de cultura opinativa implicado constantemente pela globalização, quando não se possui embasamento e escopo, acaba por fazer com que o jovem se sinta perdido, aturdido, incompreendido - ainda para os jovens que percebem, de algum modo, esta dinâmica. Porque, a imensa maioria, vive dentro desta lógica contínua e nem mesmo se dá conta.

Neste contexto, o jovem torna-se motor de dúvidas, angústias e expositor de conflitos intra e interpessoais. Em consequência, a vida torna-se um fardo e, esses jovens

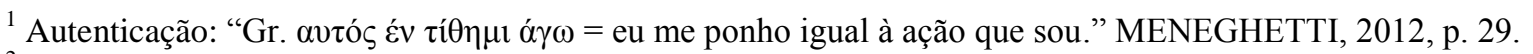

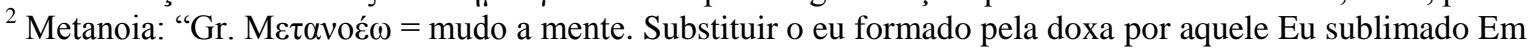
Si ôntico. MENEGHETTI, 2012, p. 172.

${ }^{3}$ Em Si ôntico: "Projeto-base de natureza que constitui o ser humano. Princípio formal inteligente que faz Autócitse Histórica.” MENEGHETTI,2012, p. 84.
} 
desiludidos na vida, buscam saciar o vazio interior em desculpas evasivas ditadas pela doxa da sociedade, na tentativa de compensar o início da perda de identidade ${ }^{4}$.

Neste trabalho de pesquisa, temos por objetivo geral compreender quais são os principais estereótipos que consomem a potencialidade do jovem, acabando por inferiorizá-lo diante da vida.

O tipo de pesquisa empregada para realizar este trabalho foi o estudo teórico. Além disso, foi elaborado um breve relato/depoimento acerca do percurso formativo da jovem autora deste trabalho.

\section{Fundamentação Teórica}

Discutir sobre a formação do jovem implica diretamente no fato de que existimos. Estamos vivos, cada um de nós é uma realidade no cosmo infinito. O cosmo: ondas de energia ordenada. Embora essas ondas pareçam aparentemente confusas. Todas são universais, ou seja, todas convergem em uma unidade de ordem.

Nessa ordem cósmica, cada um de nós existe, é uma realidade, não é um nada. Fomos quistos pela vida, pelo espaço infinito de energia inteligente do universo. Quando nascemos somos plenamente conscientes, não existe o inconsciente, portanto as pulsões vitais são refletidas tais como são. Mas em nosso entorno existe a sociedade, que influencia diretamente na nossa construção. Conforme vamos crescendo, chega-se a um momento em que encontramos dificuldades em saber o que realmente somos, pois em nosso inconsciente, a partir do contato com a sociedade, já se instalou o monitor de deflexão ${ }^{5}$, impedindo que os instintos de vida cheguem até nosso consciente, e também que possamos nos construir como pessoas íntegras.

Neste trabalho de pesquisa consideramos que o jovem saudável é aquele que tem suas inquietações, que as busca, que de alguma forma tenta saciar essa sede de saber que ele mesmo desconhece de onde vem, entendemos "jovem" como:

...é aquele que tem ainda a atividade, a iniciação do próprio princípio causal: o Em Si ôntico, ou seja, algo ainda mais preciso do que aquilo que se entende como alma: é a capacidade iniciática ao fazer em progresso, em sucesso, em

\footnotetext{
${ }^{4}$ Identidade: "Lat. Id quod est ens = o que o ser é aqui, assim e agora. É a forma que especifica em si o objeto ou indivíduo e o distingue de qualquer outro." (MENEGHETTI, 2012, p. 130)

${ }^{5}$ Engenho psicodélico que desvia o sujeito da realidade da informação. Portanto, distorce, deflete a informação. Mais em: MENEGHETTI, A. Dicionário de Ontopsicologia. Recanto Maestro: Ontopsicológica Editora Universitária: 2012, p.175.
} 
evolução sobre todos os pontos de vista. O "jovem” tem uma técnica que é capaz de formalizar o élan vital, o jato do que a vida, no principiar-se, expõe como próprio escopo e investimento (MENEGHETTI, 2005, p. 343).

Em contrapartida, como dissemos anteriormente estamos inseridos em uma sociedade onde, por vezes, estas inquietações são respondidas de formas inadequadas, uma vez que o jovem instigado em descobrir, coloca os adultos em crise, pois estes, acabaram por ofuscar a mesma sensibilidade imperiosa que possuíam.

Interiorizando estas respostas inadequadas desde a infância, o jovem acaba por tornar-se esquizofrênico - ressaltamos a hipergratificação como principal agente deste fenômeno. De um lado possui consciência de uma plenitude, de outro, descobre-se dentro de um contexto que impõe as suas regras, os seus programas, os seus juízos de valor. No final ainda que relute, o jovem acaba interpretando a si mesmo em conformidade aos ditames sociais. Faz a leitura e direciona sua força baseado nos modelos de comportamento que assimilou.

Crise, angústia, insegurança, incerteza tornam-se inevitáveis quando esta dinâmica passa a ser mais presente no cotidiano do jovem, e o jovem agarra-se a desculpas evasivas, organizando a vida de acordo com o que a sociedade dita. Por fim, o jovem se enquadra, por vezes sem saber, nos chamados estereótipos, que são modelos de comportamento fixos que se fazem referência de outros semelhantes e que se tornam valor de apoio para individuar segurança e razão dialética com a sociedade.

Os estereótipos podem ser funcionais quando não são utilizados pelo ser humano de modo absoluto, ou seja, quando são aplicados de acordo com o resultado. A Escola Ontopsicológica explica que existem três principais comportamentos-base regressivos para o jovem, comportamentos esses que estandardizam uma consciência e tornam-na incapaz de se autoproduzir em conformidade a própria identidade: Biologismo; Idealismo Critico e Consumismo (MENEGHETTI, 2013).

\subsection{Biologismo}

No biologismo, acontece uma ênfase excessiva ao corpo, exaltando-se prazeres que lhe são conexos: sexo, segurança, não trabalho, comodidade entre outros. Pode se manifestar das seguintes formas:

\subsubsection{Biologismo como corpo}


O jovem formaliza seu projeto moral a partir de uma realidade biológica, perdendose a dimensão espiritual. Substancialmente, deixa-se caracterizar pela posição do corpo físico, baseando a formalização de uma ideia de acordo com essa caracterização. Mas o corpo é apenas o depositário do espirito humano. Como consequência, a evolução da pessoa espiritual, intelectual, volitiva, livre, crítica construtiva e moral não pode acontecer, pois não são realizados os projetos e os valores que qualificam o homem como superior no contexto terrestre.

\subsubsection{Biologismo familístico}

O homem tem um ciclo biológico, nasce, cresce, torna-se adulto, casa, constitui família, educa os filhos conforme a sociedade e basta.

\subsection{Idealismo Crítico}

Por meio do idealismo crítico, desloca-se o próprio empenho de crescimento evolutivo no fazer racionalismos críticos em relação aos defeitos alheios. Um exemplo, é o posicionamento crítico dos jovens em relação ao comportamento dos pais. O jovem evita a tarefa e o sacrifício de construir a si mesmo, observando os erros dos adultos. Cria-se, então, no jovem um estado de gratuita segurança e superioridade, reforçada pelos erros, limites e problemas dos adultos. Contudo, deve-se considerar que os adultos, mesmo sendo corruptos, podem passar instrumentos de trabalho e um saber técnico que o jovem poderá usar de modo aprimorado no futuro (MENEGHETTI, 2013).

Essa percepção de gratuita segurança e superioridade leva o jovem à estagnação, estabilizando essa consciência como memória. Acreditando ser já bem-sucedido perde passagens que o instrumentalizaria e se evade das suas responsabilidades. Como consequência, o jovem não constrói a si mesmo. No fim a superioridade idealística inicial se torna sua armadilha futura. Sem investimento e realização de si mesmo, o jovem não consegue ser grande.

\subsection{Consumismo}


Vive-se numa sociedade consumista, onde os indivíduos se empenham para ter a melhor imagem possível em relação a símbolos de status correntes na sociedade. Assim, adquirem bens de uso comum, sem a evidência de utilidade desses bens para si. Logo as multinacionais crescem, associadas a massa de jovens que pensam ser consumidores, mas na verdade estão sendo mercantilizados pela carência de informação que resulta na necessidade de ter a melhor imagem possível perante a sociedade para sentir-se "bem".

Agregados a esses três estereótipos, em conjunto ou isoladamente, unem-se os principais vícios da juventude: sexomania, toxicodependência alcoolismo, antissociabilidade (delinquência), psicossomática grave e uso superficial da tecnologia digital. O jovem mesmo acaba construindo a sua falência. Em suma, a juventude se encontra limitada e não consegue mais ter uma vida sadia, muito menos de valor, porque perdeu a destinação. (MENEGHETTI, 2013).

O jovem vegeta biologicamente no ciclo de estereótipos e vícios sem a conexão com o próprio real. O mesmo sofre, sem saber, da chamada esquizofrenia existencial: é de um modo, e se pensa de outro. Sua consciência não reflete a informação real, em função do monitor de deflexão, gerando comportamentos não côngruos com própria identidade consomem a sua potencialidade, os distanciando cada vez mais da realização pessoal.

$\mathrm{Na}$ existência, ou se atinge o escopo para o qual fomos postos, ou então a vida é estúpida. Exatamente como pegar o trem tem uma finalidade, se existir um destino preciso no passageiro. Se o destino não é exato na intenção do passageiro, então todo o seu gerir não só é sem destino como o fato em si, mas ele próprio se torna concreto de insipiência. A existência tem sentido somente se a radicalidade do Ser está presente e é sentida. (MENEGHETTI, 2004, p. 147).

\subsection{A solução ontopsicológica}

A Escola Ontopsicológica propõe a refundação da pessoa ontológica, através de um processo de consultoria de autenticação. Visando evidenciar como o Eu Lógico histórico administra a sua existência.

É o Eu Lógico histórico que precisa mudar, são os próprios hábitos dentro dos quais se protege a si mesmo que devem ser modificados, a fim de que realize autóctise histórica e haja reversibilidade entre o Em Si ôntico e o Eu Lógico histórico. 


\subsection{A responsabilidade pessoal}

Considerando que a sociedade é produto daqueles que a forma, entendemos que se faz fundamental que, principalmente, os jovens hajam com responsabilidade perante a própria vida. À fim de manter a integridade pessoal e assim, contribuir com uma sociedade melhor.

É necessário que o jovem não desperdice a si mesmo, ele deve agir incansavelmente em função de seu crescimento. Deve aproveitar o período em que tudo lhe é dado de forma mais fácil e absorver todos os instrumentos de progresso possíveis. Do contrário, os anos passam, e se não houve investimento o jovem é carente de autonomia econômica e autonomia de existência.

A juventude é o período de maior virtualidade de um indivíduo em que tem a potencialidade de aprender e produzir qualquer coisa, portanto o mesmo, se deseja tornarse grande, deve estudar e aprender o máximo possível em relação ao que lhe interessa, bem como aspectos de cultura geral. Ele também necessita realizar ações práticas para que aprenda sobre si mesmo e para que possa saber os modos instrumentais para operar com superioridade em diversos campos. (MENEGHETTI, 2010).

\section{Resultados e Discussão}

Mesmo considerando que este trabalho de pesquisa está em processo/andamento, e que este é um estudo teórico, nos propomos neste momento - tendo em vista o tema escolhido para escrever o mesmo - em apresentar um breve relato pessoal, como contribuição exemplificativa de um percurso inicial de formação como jovem protagonista responsável.

Analisando, com muita humildade a mim mesma, verifico que antes de começar a estudar na Faculdade Antonio Meneghetti, posso me definir como uma jovem que reivindicava suas vontades, mas que não dava o melhor de si, no pouco que fazia. Recordo-me que em um período pensava que meus pais tinham obrigação de dar-me o que eu queria, e também, de deixarem-me fazer o que queria e em resposta à isso meus pais me expunham seus conceitos de valor, mas que, naquele tempo, não me pareciam serem convincentes aos meus questionamentos. Neste contexto, realizei passagens inadequadas, as quais não eram saldáveis a mim mesma, nem aos meus familiares. Hoje, após 
aproximadamente 6 meses residindo no Centro de Formação Humanista Recanto Maestro como acadêmica da $2^{\text {a }}$ Turma do Curso de Bacharelado em Ontopsicologia, evidencio mudanças significativas em meu comportamento. Aqui saliento a que considero de maior valia: Começar a colocar-me como jovem responsável pela a própria vida, respondendo em primeira pessoa pelos meus atos, afim de dar início a arte intrínseca de viver de acordo a lógica da vida, e assim tornar-me coeficiente de valor na sociedade. Cabe a cada um de nós a tarefa de modificar o mundo, o que só conseguiremos a medida em que formos modificando a nós mesmos.

Além disso, esse projeto de pesquisa foi adaptado e enviado a Banca de Avaliação do II Congresso Internacional Uma Nova Pedagogia para a Sociedade Futura, sendo aprovado e apresentado na categoria banner.

\section{Considerações Finais}

Tendo como referência o texto a cima discorrido, percebe-se que muitos dos comportamentos que caracterizam a situação existencial da juventude, têm início com a influência inadequada da sociedade, que traz à juventude a sequência de sua vivencia não aceitação, não compreensão e por fim a perdição. Uma vez que a sociedade já não compreende a ânsia e a beleza que remete a busca da juventude, pois não a possui mais, acontecem sucessivas repreensões acerca do pensamento jovem, que tende a vegetar como um precoce velho dentro do triângulo de estereótipos que consome a sua potencialidade.

Se faz fundamental que o jovem mantenha o estímulo vivo que porta dentro de si sem interiorizar as respostas inadequadas da sociedade, aprendendo a relativizar e transcender os diversos estereótipos de forma que reforcem a ação viva que tem dentro si. Sem esta ação viva o jovem não pode construir uma existência de valor, não consegue ser plenamente realizado. E é esta ação viva que, na juventude, é plenamente sentida, portanto, deve ser compreendida e reforçada, e não evitada ou enlatada em estereótipos. Salientamos não se trata de fazer revolução externa e sim interna. Relativizando estas respostas e trabalhando em prol do seu crescimento, o jovem logo construirá a si mesmo com superioridade. 


\section{Referências}

MENEGHETTI, A. Da consciência ao ser. Como impostar a filosofia do futuro. Recanto Maestro: Ontopsicológica Editora Universitária, 2014.

MENEGHETTI, A. Dicionário de Ontopsicologia. 2. ed. Recanto Maestro: Ontopsicologia Editrice, 2008.

MENEGHETTI, A. Do Humanismo Histórico ao Humanismo Perene. Recanto Maestro: Ontopsicológica Editora Universitária, 2014.

MENEGHETTI, A. Os jovens e a ética ôntica. Recanto Maestro: Ontopsicológica Editora Universitária, 2013.

MENEGHETTI, A. Manual de Ontopsicologia. 4. ed. Recanto Maestro: Ontopsicologica Editrice, 2010.

MENEGHETTI, A. Nova Fronda Virescit. Introdução à Ontopsicologia para jovens. Vol. I. Recanto Maestro: Ontopsicologica Editrice, 2010.

MENEGHETTI, A. Sistema e personalidade. Recanto Maestro: Ontopsicologica Editrice, 2004.

BARBIERI, J. A Juventude. In: Fundação Antonio Meneghetti. Uma Nova Pedagogia Para a Sociedade Futura: Princípios Práticos. Recanto Maestro: Ontopsicológica Editora Universitária, 2015. 